\title{
Erratum to: Pornography and the Male Sexual Script: An Analysis of Consumption and Sexual Relations
}

\author{
Chyng Sun $^{1} \cdot$ Ana Bridges ${ }^{2} \cdot$ Jennifer A. Johnson $^{3} \cdot$ Matthew B. Ezzell $^{4}$
}

Published online: 29 March 2016

(c) Springer Science+Business Media New York 2016

\section{Erratum to: Arch Sex Behav \\ DOI: 10.1007/s10508-014-0391-2}

Following is the correct rendering of the names of the third and fourth authors of this article:

\section{Jennifer A. Johnson}

Matthew B. Ezzell

The article's abstract also contains an error. In the last sentence in the first column, instead of:
Results showed the more pornography a man watches, the more likely he was to use it during sex, request particular pornographic sex acts of his partner, deliberately conjure images of pornography during sex to maintain arousal, and have concerns over his own sexual performance and body image.

It should read:

Results showed the more pornography a man watches, the more likely he was to use it during sex, request particular pornographic sex acts of his partner, and deliberately conjure images of pornography during sex to maintain arousal.

The online version of the original article can be found under doi:10.1007/ s10508-014-0391-2.

Chyng Sun

cfs1@nyu.edu

1 School of Professional Studies, New York University, New York, NY 10012, USA

2 Interpersonal Systems Laboratory, Department of Psychological Science, University of Arkansas, Fayetteville, AR, USA

3 College of Humanities and Sciences, Virginia Commonwealth University, Richmond, VA, USA

4 Department of Sociology \& Anthropology, James Madison University, Harrisonburg, VA, USA 